\title{
Experimental study on thermal, rheological and filtration control characteristics of drilling fluids: effect of nanoadditives
}

\author{
Erfan Veisi, Mastaneh Hajipour*, and Ebrahim Biniaz Delijani \\ Department of Petroleum Engineering, Faculty of Petroleum and Chemical Engineering, Science and Research Branch, \\ Islamic Azad University, 1477893855 Tehran, Iran
}

Received: 12 March 2020 / Accepted: 28 April 2020

\begin{abstract}
Cooling the drill bit is one of the major functions of drilling fluids, especially in high temperature deep drilling operations. Designing stable drilling fluids with proper thermal properties is a great challenge. Identifying appropriate additives for the drilling fluid can mitigate drill-bit erosion or deformation caused by induced thermal stress. The unique advantages of nanoparticles may enhance thermal characteristics of drilling fluids. The impacts of nanoparticles on the specific heat capacity, thermal conductivity, rheological, and filtration control characteristics of water-based drilling fluids were experimentally investigated and compared in this study. $\mathrm{Al}_{2} \mathrm{O}_{3}, \mathrm{CuO}$, and $\mathrm{Cu}$ nanoparticles were used to prepare the water-based drilling nanofluid samples with various concentrations, using the two-step method. Transmission Electron Microscopy (TEM) and X-Ray Diffraction (XRD) were utilized to study the nanoparticle samples. The nanofluids stability and particle size distribution were, furthermore, examined using Dynamic Light Scattering (DLS). The experimental results indicated that thermal and rheological characteristics are enhanced in the presence of nanoparticles. The best enhancement in drilling fluid heat capacity and thermal conductivity was obtained as $15.6 \%$ and $12 \%$, respectively by adding $0.9 \mathrm{wt} \% \mathrm{Cu}$ nanoparticles. Furthermore, significant improvement was observed in the rheological characteristics such as the apparent and plastic viscosities, yield point, and gel strength of the drilling nanofluids compared to the base drilling fluid. Addition of nanoparticles resulted in reduced fluid loss and formation damage. The permeability of filter cakes decreased with increasing the nanoparticles concentration, but no significant effect in filter cake thickness was observed. The results reveal that the application of nanoparticles may reduce drill-bit replacement costs by improving the thermal and drilling fluid rheological characteristics and decrease the formation damage due to mud filtrate invasion.
\end{abstract}

\section{Introduction}

Cooling is an important challenge in various industries, including the drilling industry. Drilling fluids have this primary important function in subsurface wellbore drilling operations and help prevent the costly bit failures that occur while crushing rigid rocks, at high temperature, and at the great depth [1]. Therefore, these fluids must be designed in a way that they can perform in complex subsurface environments efficiently and without damaging the formations.

Drilling for oil and gas is achieved with the use of a drill bit connected to a kilometers length drillstring. The drilling fluid is pumped through this drillstring and is continually in contact with the bottom of the bore hole through the drill bit nozzles. This circulating drilling fluid cools and lubricates the drill bit and helps to convey drill cuttings to the surface. One of the major challenges in designing drilling

\footnotetext{
* Corresponding author: m.hajipour@srbiau.ac.ir
}

fluid formulations is the requirement for the highest degree of thermal stability under High-Pressure High-Temperature (HPHT) conditions. To obtain the necessary stability and performance requires appropriate additives to improve the thermal and rheological characteristics of the drilling fluid; here, nanotechnology offers a promising approach $[2,3]$.

Nanofluids are defined as a mixture of nano sized particles suspended and stabilized in a base fluid. Nanoparticles presence in a fluid enhances the rheological, mechanical, and thermal properties. Suspensions of nano-sized particles can augment fluid stability and reduce flow-passages blockage [4]. Nanoparticles, with high surface-to-volume ratio, show enhanced physico-chemical properties compared to other fluids which introduce them as the best materials for synthesis of smart drilling fluids with favorite characteristics during drilling.

Several factors such as their thermal conductivity, rheology, density, heat capacity, and diffusion coefficient, affect the heat transfer characteristics of nanofluids. Although several studies have been conducted on drilling 
fluid thermal conductivity, investigations on the nanoparticles effects on drilling nanofluid heat capacity are scarce and little information is available. Nanofluids with higher heat capacities are necessary to enhance heat transfer efficiency at lower operating costs.

According to Newton-Richman's law, the convective heat transfer rate of a solid body and its adjacent fluid is proportional to the heat transfer coefficient, surface area and their temperature difference. Therefore, the heat transfer rate from a drill-bit can be enhanced by making temperature difference increase between the bit and drilling fluid. Hence, designing a drilling fluid with high specific heat capacity leads to efficient cooling of the drill-bit [5].

In the case of the thermal behavior of drilling fluids, improvement of thermal conductivity with the use of nanoparticles has been widely investigated. The presence of nanoparticles in base fluids is known to enhance rheological behaviors and thermal conductivities [6-9], but studies on the drilling fluids specific heat capacity have not yielded consistent outcomes [10-16].

William et al. investigated the influence of copper and zinc based nanoparticles in water-based nanofluids. The results of their experiments showed up to $53 \%$ and $23 \%$ improvement in the drilling fluids thermal conductivity, respectively [17]. Sadegh et al. conducted experiments with adding multiwall carbon nanotube, nano zinc oxide and silica nanoparticles to water-based drilling fluids, and reported $12 \%, 22 \%$, and $16.9 \%$ improvement in the thermal conductivity of drilling fluid at a $2 \%$ volume fraction of these nanoparticles, respectively [18]. Baghbanzadeh et al. produced sphere-shaped silica-multiwall carbon nanotube hybrid and prepared nanofluids to examine the thermal conductivity variations. They indicated that the nanoparticle concentration and amount affect the nanofluids thermal conductivity [19].

In previous studies it is reported that the rheological properties and thermal conductivity of drilling fluid can be improved by using nanoparticles [20-24]. However, investigation of the drilling fluid specific heat capacity as an essential factor for proper drill-bit cooling especially in deep drilling operations is scarce in the literature.

In this study, the influence of various nanoparticles on the enhancement of drilling fluid thermal, rheological and filtration properties was investigated experimentally. To this end, three types of nanoparticles were used to prepare drilling nanofluid samples. The nanoparticles were studied by Transmission Electron Microscopy (TEM) and X-Ray Diffraction (XRD). Various nanoparticles concentrations were stabilized in distillated water and homogenized in drilling fluid. The particle size distribution of nanoparticles were investigated using Dynamic Light Scattering (DLS) method. Thermal characteristics such as thermal conductivity and specific heat capacity were measured using Differential Scanning Calorimetry (DSC) and Hot Wire techniques, respectively. Rheological characteristics were experimentally measured including apparent and plastic viscosities, gel strength and yield point of drilling fluid in the presence of nanoparticles. Also, the drilling nanofluids filtration loss was studied to evaluate the effect of nanoparticles in formation damage reduction, and its influence on the permeability and thickness of mud cakes were compared.

\section{Experimental procedure}

\subsection{Drilling nanofluid preparation}

Analysis of nanofluids properties requires proper preparation of a stable nanoparticles suspension in water. One-step or two-step method can be used to prepare the nanofluid. In the first method, by means of chemical methods, nanoparticles are produced in a base fluid [25]. In the second method, first powder nanoparticles are produced and then the nanofluid suspension is created by mixing this powder with a base fluid [26]. While nanopowders can be produced in large scales, the nanofluids prepared by the second method may be produced in lower costs and this method is more common. A main problem in working with nanofluids is the tendency of nanoparticles to agglomerate due to their large and active surface area. Some mixing methods such as sonication, $\mathrm{pH}$ adjustment and addition of a stabilizers, should be used to stabilize these mixtures [27].

The nanoparticles used in this study are aluminum oxide $\left(\gamma-\mathrm{Al}_{2} \mathrm{O}_{3}\right)$, copper $(\mathrm{Cu})$ and copper oxide $(\mathrm{CuO})$. These nanoparticles were selected for their excellent thermal properties compared to other solids. The nanoparticles were provided from US Research Nanomaterials, Inc. and their properties are shown in Table 1 . The nanoparticles were characterized by XRD 3003 PTS, Philips to verify the nanoparticles' size, shape and purity.

To prepare water-base drilling fluid, $350 \mathrm{~mL}$ of distilled water and $24 \mathrm{~g}$ bentonite were mixed and stirred with Fann Multi Mixer (model 9B29X) for at least $15 \mathrm{~min}$. The standard two-step procedure was used to make the nanofluid samples. First, nanoparticles were dispersed in distilled water in a certain concentration to prepare the nanofluids. Then, the mixture was stirred thoroughly and was sonicated using an ultrasonic disruptor (Elmasonic, E $30 \mathrm{H}$ ) for $120 \mathrm{~min}$, resulting in homogeneous and stable nanofluids. The nano suspensions were added to the base drilling fluid and each sample stirred with a high speed mixer (Fann Multi Mixer, 9B29X) for at least 5 min to produce uniform suspension. Drilling nanofluid samples were prepared in different concentrations below $1 \mathrm{wt} \%$ (i.e., 0.3, 0.6, and $0.9 \mathrm{wt} \%$ ). The Particle Size Distribution (PSD) analysis for prepared nanofluids was conducted by dynamic light scattering method (DLS SZ-100z, Horiba).

\subsection{Thermal and rheological properties measurement}

Mettler Toledo DSC calorimeter system at a heating rate of $10{ }^{\circ} \mathrm{C} / \mathrm{min}$ was utilized to measure the specific heat capacity of the base drilling fluid and samples with nanoparticles from $10{ }^{\circ} \mathrm{C}$ to $70{ }^{\circ} \mathrm{C}$. The three step DSC procedure based on ASTM Standard E1269 was followed for specific heat capacity measurement [28].

In the first step, the base heat flux $\left(Q_{\mathrm{b}}\right)$ was recorded with two empty pans loaded into the DSC in a specified temperature range. The value of the base heat flux specifies 
Table 1. The properties of nanoparticles.

\begin{tabular}{lcccc}
\hline Nanoparticle & Purity & Density $\left(\mathrm{g} / \mathrm{m}^{3}\right)$ & Heat capacity $\left(\mathrm{J} / \mathrm{g}{ }^{\circ} \mathrm{C}\right)$ & Morphology \\
\hline $\mathrm{Al}_{2} \mathrm{O}_{3}$ & $99.8 \%$ & 3.9 & 0.88 & Spherical \\
$\mathrm{CuO}$ & $99 \%$ & 6.5 & 0.54 & Nearly spherical \\
$\mathrm{Cu}$ & $99.5 \%$ & 8.9 & 0.42 & Spherical \\
\hline
\end{tabular}
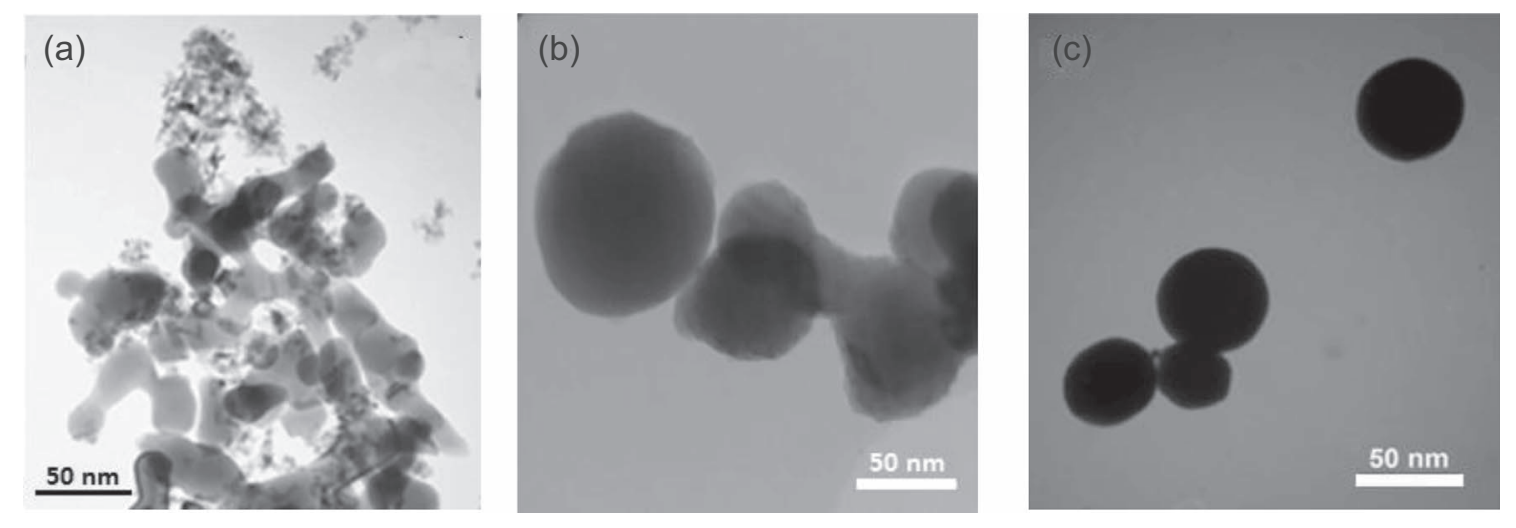

Fig. 1. TEM images of: (a) $\mathrm{Al}_{2} \mathrm{O}_{3}$, (b) $\mathrm{CuO}$, and (c) $\mathrm{Cu}$ nanoparticles.

the device bias. The second step was the measurement of heat flux into distilled water as a reference sample $\left(Q_{\text {ref }}\right)$ in the identical temperature range. In the last step, the heat flux into the drilling mud sample $(Q)$ was measured in the temperature range similar to the previous steps. Finally, for the drilling fluid and different nanofluid samples, the specific heat capacity was calculated based on equation (1):

$$
\frac{C_{p}}{C_{p, \text { ref }}}=\frac{m_{\mathrm{ref}}\left(Q-Q_{\mathrm{b}}\right)}{m\left(Q_{\mathrm{ref}}-Q_{\mathrm{b}}\right)}
$$

$m$ is the mass of drilling mud sample and $m_{\text {ref }}$ is the mass of the reference.

For each concentration of the nanofluid samples, measurements were taken three times, and the calculated specific heat capacities were then averaged to yield the final value. To check the device calibration and the accuracy of obtained data, the specific heat capacity of distilled water was measured with this method and the measured value was compared with the value reported in the references [29].

For thermal conductivity measurement, KD2 Pro (Decagon) apparatus was used which operates based on the Transient Hot Wire (THW) method which is one of the most accurate techniques for determining thermal conductivity of various materials. The detailed principles are available in the literature [30]. The instrument was calibrated using distilled water before performing drilling fluid measurements.

The rheological characteristics of the base drilling fluid and other nanofluid samples were measured in accordance with the American Petroleum Institute (API) standards [31]. To perform rheological analysis, the drilling fluid's properties including the Apparent Viscosity (AV), Plastic Viscosity (PV), Yield Point (YP), and Gel Strength (GS) were measured. A rotational viscometer (OFITE, model
800) was used to obtain the rheological properties of all drilling fluids samples. To homogenize the drilling fluid, before starting the measurement, the samples were stirred for $5 \mathrm{~min}$. To ensure the repeatability of the measurements, each test was performed three times. The shear stress-shear rate relationship for drilling fluid samples was investigated using Anton Paar rheometer (MCR 302).

\subsection{Filtration test}

The filtration properties of the drilling fluid samples with and without the presence of nanoparticles were measured using OFITE Filter Press. The static filtration test was carried out at the temperature of $25{ }^{\circ} \mathrm{C}$ and the pressure of $100 \mathrm{psi}$ according to the API standard procedure (API $R P$ 13B-1). Three hundred milliliters of the drilling fluid was loaded into the filtration cell and for each sample, the volume of liquid filtrate collected in a graduated cylinder under the filter cell was measured after $30 \mathrm{~min}$. At the end of the experiments, the filter cakes were taken out from the cells carefully and their thickness was recorded.

\section{Results and discussion}

\subsection{Nanoparticles and nanofluids characterization}

Figure 1 represents the TEM images of nanoparticles. The figure illustrates that the nanoparticles are in spherical shape. The average sizes of $\mathrm{Al}_{2} \mathrm{O}_{3}, \mathrm{CuO}$, and $\mathrm{Cu}$ nanoparticles observed in the images are 25, 45, and $42 \mathrm{~nm}$, respectively. The XRD pattern of nanoparticles shown in Figure 2 indicates the purity of nanoparticles. The characteristic peaks are consistent with the reference pattern for the nanoparticles from Figure 2. 

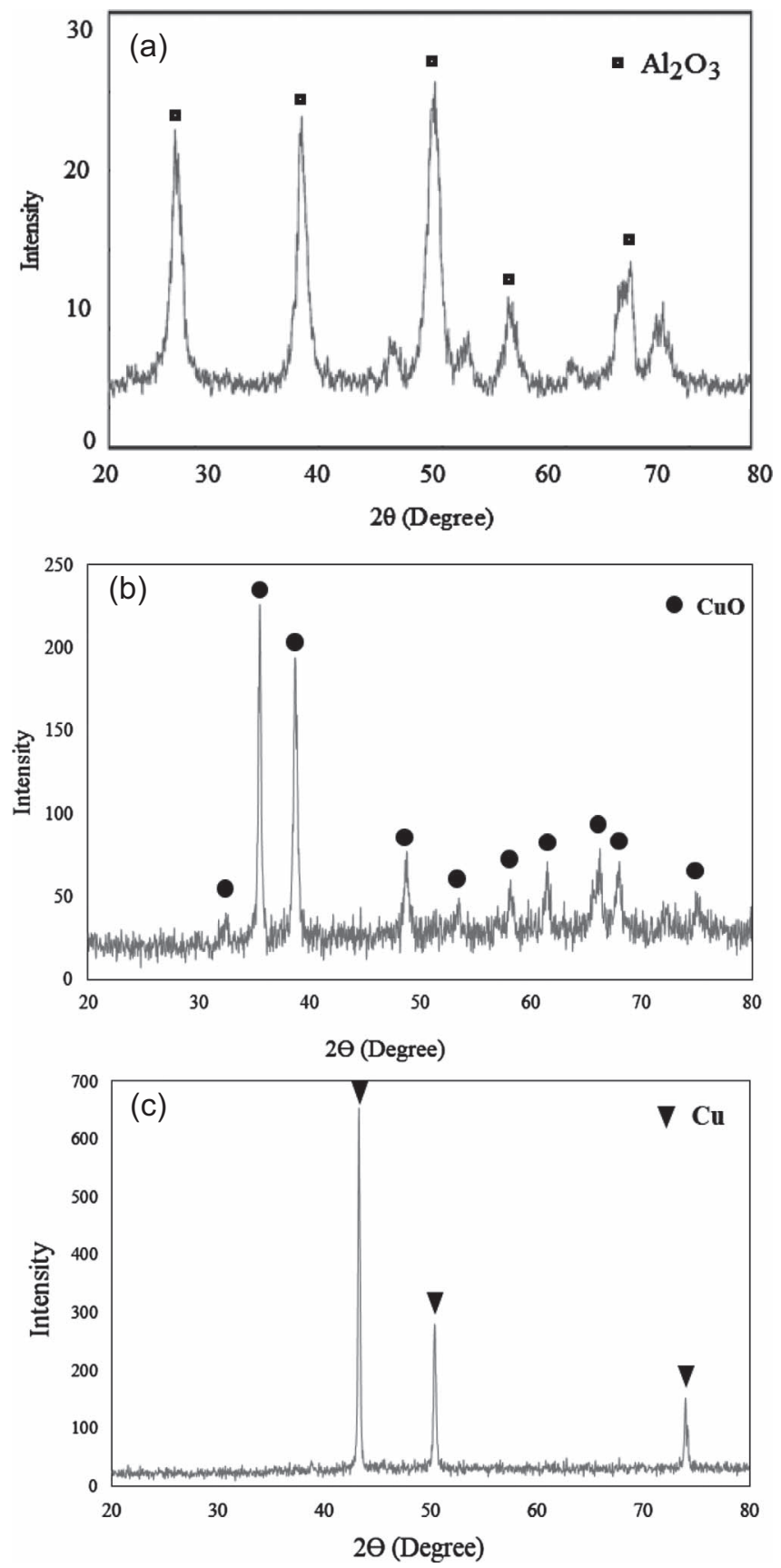

Fig. 2. XRD pattern of nanoparticles: (a) $\mathrm{Al}_{2} \mathrm{O}_{3}$, (b) $\mathrm{CuO}$, and (c) $\mathrm{Cu}$ nanoparticles.

Since nanoparticles have a tendency to agglomerate and precipitate, it is necessary to examine whether or not nanoparticles are well dispersed in the base fluid. Figure 3 compares the particle size distribution for various nanofluid samples. The average diameter of aluminum oxide, copper oxide, and copper nanoparticles are found to be 45,68 , and $55 \mathrm{~nm}$, respectively. The size distribution is found to be narrow for all nanofluid samples and the average particle size measured is smaller than $100 \mathrm{~nm}$ and confirms that a nanofluid sample has been prepared. The stability of the suspensions was investigated by performing time dependent



Fig. 3. Particle size distribution of nanoparticles.

measurements and good stability was observed during the experiments. In fact, the precipitation of nanoparticles occurs very slowly due to the existence of bentonite and the gel strength of the base drilling fluid.

\subsection{Thermal properties}

\subsubsection{Specific heat capacity}

The specific heat capacity of a body is an intensive property and does not depend on the body's mass. This thermal property shows the capacity of a body to absorb heat and depends on the temperature at which it is measured.

The accuracy of DSC measurement was initially evaluated using distillated water. The specific heat capacity of distilled water was found to be $4.20 \mathrm{~J} / \mathrm{g}{ }^{\circ} \mathrm{C}$, whereas the reference value in the literature is $4.18 \mathrm{~J} / \mathrm{g}{ }^{\circ} \mathrm{C}$ [29]. The discrepancy was $0.02 \mathrm{~J} / \mathrm{g}{ }^{\circ} \mathrm{C}$ and the relative error was assessed as $0.5 \%$. As can be seen, the measured value of distilled water specific heat capacity is in good agreement with the value reported in the literature and validates the apparatus calibration.

To provide a baseline for comparing the drilling nanofluids' data, the base drilling fluid without nanoparticles specific heat capacity was measured. Finally, the specific heat capacity of drilling nanofluids containing a type of nanoparticle i.e. $\mathrm{Al}_{2} \mathrm{O}_{3}, \mathrm{CuO}$, and $\mathrm{Cu}$ at concentrations of $0.3,0.6$, and $0.9 \mathrm{wt} \%$ were measured and compared.

The ratio of the specific heat capacity of drilling nanofluids with respect to the base drilling fluid for different concentrations of nanoparticles is shown in Figure 4. Looking at Figure 4, it is apparent that, the specific heat values of drilling nanofluids containing $\mathrm{Al}_{2} \mathrm{O}_{3}$ and $\mathrm{CuO}$ nanoparticles follow the same trend. For drilling fluid containing $\mathrm{Al}_{2} \mathrm{O}_{3}$ nanoparticles, the specific heat values decrease slightly by addition of $0.3 \mathrm{wt} \%$ nanoparticles to the base sample and then increase for higher concentrations. The maximum increase of heat capacity for $\mathrm{Al}_{2} \mathrm{O}_{3}$ nanoparticles was found at a concentration of $0.9 \mathrm{wt} \%$. Similarly, the addition of 0.3 wt $\% \mathrm{CuO}$ nanoparticles to the base drilling fluid, decreases the specific heat of drilling fluid by $1.5 \%$, but 


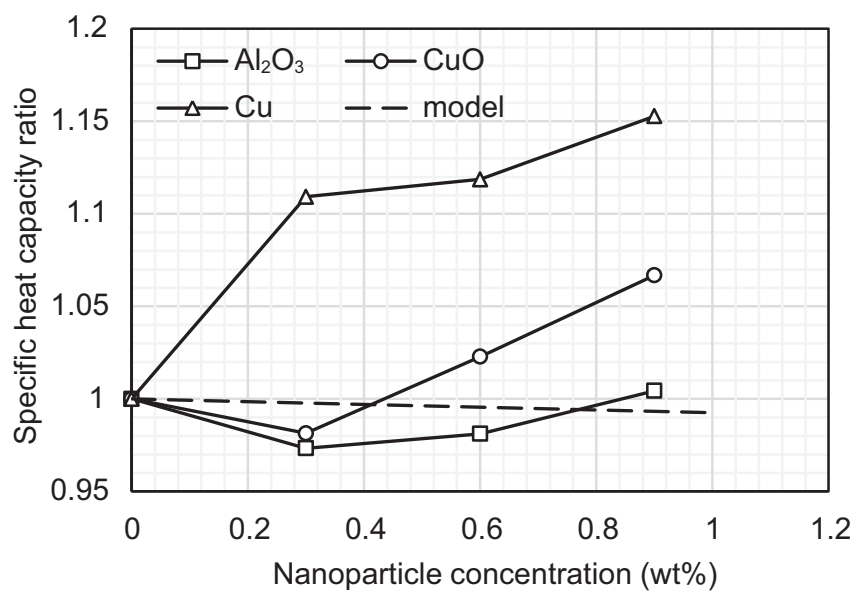

Fig. 4. Specific heat capacity of drilling nanofluids at different concentrations of nanoparticles.

higher loadings of $\mathrm{CuO}$ nanoparticles increase this property. In fact, reduction of specific heat capacity of nanofluids by adding nanoparticles is due to lower values of nanoparticles specific heat capacity compared to the base fluid. A similar decrease of specific heat capacity is reported in the literature $[32,33]$

For drilling nanofluids containing $\mathrm{Cu}$ nanoparticles, the specific heat capacity is found to increase as the nanoparticles mass fraction increases at all examined concentrations. As can be observed, the specific heat enhancement of drilling fluid in the presence of copper nanoparticles is substantially higher compared to other nanoparticles. The increasing trend of heat capacity with rising $\mathrm{Cu}$ nanoparticles concentration clearly indicates that heat capacity increment of $\mathrm{Cu}$ added drilling nanofluid is faster than that of the other two nanoparticles investigated.

In the literature several experimental observations of specific heat maximization due to change in nanoparticles concentration are reported. Chieruzzi et al. observed an initial reduction of heat capacity for nanofluids containing $\mathrm{TiO}_{2}$ and $\mathrm{SiO}_{2}$ nanoparticles [34]. The measurements of Heilmann presents a maximum heat capacity at $1 \mathrm{wt} \%$ $\mathrm{Al}_{2} \mathrm{O}_{3}$ nanoparticles [35]. Lasfargues et al. reported a specific heat capacity enhancement of $30 \%$ in $0.5 \mathrm{wt} \% \mathrm{TiO}_{2}$ nanoparticles dispersed in a binary salt mixture [36].

The experimental results indicate that for samples containing nanoparticles lower than $1 \mathrm{wt} \%$, the specific heat capacity of drilling nanofluids increases nonlinearly with an increase in the nanoparticles concentration. As can be observed from the obtained data, the addition of more than $0.3 \mathrm{wt} \%$ of nanoparticles to the base drilling fluid causes the specific heat capacity to increase. The maximum heat capacity enhancement, i.e. $15.6 \%$, was found with addition of $0.9 \mathrm{wt} \%$ of $\mathrm{Cu}$ nanoparticles. The maximum standard deviation of heat capacity measurement for various drilling nanofluid samples was calculated as 0.03 .

The increase in heat capacity of the drilling fluid due to addition of nanoparticles proves that nanoparticle enhanced drilling fluid can absorb more heat from the drill-string and bit than conventional drilling fluids. This property is more significant for cooling functionality in deep drilling operations. One of the mechanisms considered for the increase of the specific heat capacity in nanofluids is the enhanced specific heat capacity of nanoparticles due to their higher specific surface energy compared with bulk material. Moreover, additional thermal storage mechanisms due to the high specific surface area of the nanoparticles, and the interfacial interactions between nanoparticles and fluid molecules, affect the nanofluid thermal properties. Another mechanism is the creation of a nanolayer of nanoparticles on the surface, which is likely to enhance specific heat capacity due to the smaller intermolecular spacing compared to the higher intermolecular spacing in the bulk liquid [37, 38].

The nanofluids thermal conductivity improvement has been interpreted by different mechanisms based on the Brownian motion of nanoparticles [39], aggregation of nanoparticles [40], and formation of a nanolayer [41, 42]. Among these mechanisms, the nanolayer effect is declared to be the most important factor affecting the specific heat capacity of nanofluids [42]. However, a molecular theory explaining the interfacial thermal characteristics and the effects of nanoparticles on the specific heat capacity of these fluids does not yet exist.

The specific heat capacity of nanofluids can be predicted using different models. One of the models widely used in the literature for calculation of nanofluids specific heat is as follows [43]:

$$
C_{p, n f}=\frac{\varphi\left(\rho C_{p}\right)_{n}+(1-\varphi)\left(\rho C_{p}\right)_{f}}{\varphi \rho_{n}+(1-\varphi) \rho_{f}} .
$$

This model is based on the assumption of thermal equilibrium between the solid particles and the surrounding fluid, using classical and statistical mechanics. In this model, the effect of the particle and fluid densities ( $\rho_{n}$ and $\rho_{f}$, respectively) on the specific heat of the nanofluid are taken into account.

The dashed line in Figure 4 shows the results of this model. The reduction in the specific heat capacity of the nanofluids obtained from the model is clearly explained since the specific heat capacity of the nanoparticles is significantly below the specific heat capacity of the base fluid. This behavior was also reported in previous studies $[38,44]$. As can be seen, the model prediction largely differs from the experimental data. It can be concluded that for low mass fraction of nanoparticles, the model results cannot be reliable.

\subsubsection{Thermal conductivity}

Figure 5 illustrates the ratio of the thermal conductivity of nanofluid samples with respect to the base drilling fluid against nanoparticle loadings. In Figure 5, the thermal conductivity of drilling nanofluids increases with increasing of nanoparticles content. A similar trend was reported by Farbod et al. for $\mathrm{CuO}$ nanoparticles of concentration ranging from $0.2 \mathrm{wt} \%$ to $6 \mathrm{wt} \%$ [45]. Wang et al. reported that the thermal conductivity enhancements of nanofluids depend strongly on the volume fraction of nanoparticles and increase with increasing nanoparticles loading [46]. However, increasing nanoparticles concentration decreases 


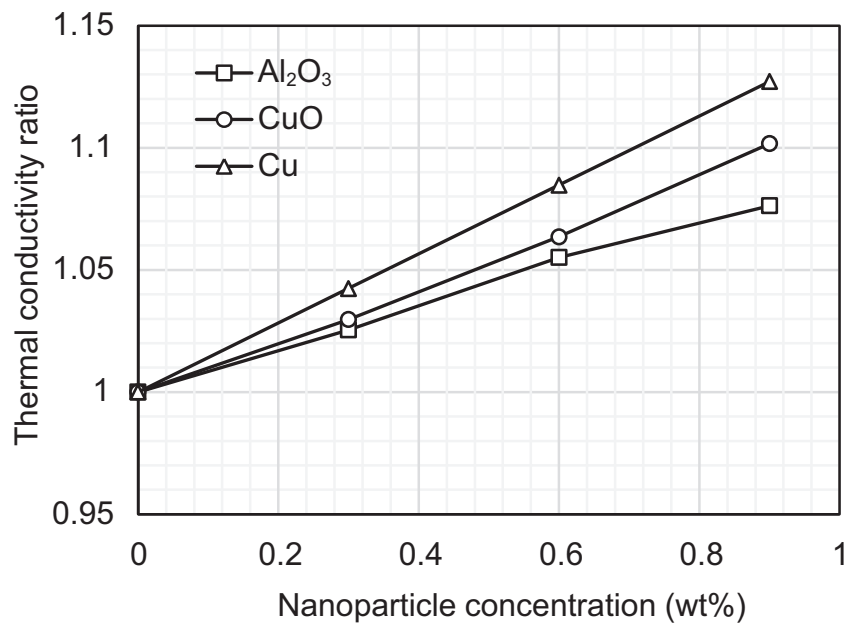

Fig. 5. Thermal conductivity of drilling fluid at different concentrations of nanoparticles.

the distance between particles while random collision due to Brownian motion accelerates agglomerations of nanoparticles [47].

As can be seen in Figure 5, the thermal conductivity enhancement for drilling nanofluids is linear for mass fractions lower than $1 \%$. From the obtained results, nanofluids containing copper nanoparticles have a higher thermal conductivity than other nanofluid samples due to higher thermal conductivity of solid dispersed particles. The maximum improvement in drilling fluid thermal conductivity was found with the addition of $0.9 \mathrm{wt} \%$ of $\mathrm{Cu}$ nanoparticles. The maximum standard deviation of thermal conductivity measurement was 0.02 . Therefore, the measurement uncertainty in the experiments is lower than $2 \%$.

\subsection{Rheological properties}

In non-Newtonian drilling fluids, it is often expected that the viscosity should decrease with increase in shear. High apparent viscosity of these fluids at low speeds is required to prevent the cuttings from falling down especially when the pumps are off and its low apparent viscosity at high speeds is required for the pump to be able to circulate it in the deep wells.

The fluids rheological behavior is reported as a plot of shear stress versus shear rate. For Newtonian fluids, the ratio of shear stress to shear rate is defined as viscosity which is a measure of resistance between the fluid's adjacent layers during flow [48]. Several mathematical models that describe the behavior of non-Newtonian fluids are available. To determine which model is most appropriate to the drilling fluid samples, the shear stress over a range of shear rates was measured. The results for drilling nanofluid samples that included $0.9 \mathrm{wt} \%$ nanoparticles are shown in Figure 6.

It is obvious from Figure 6a that adding the nanoparticles to the drilling fluid increases the shear stress. The experimental data shows that for all drilling fluid samples, the variation of shear stress with shear rate is not linear and exhibits viscoplastic shear thinning behavior.


Fig. 6. (a) Shear stress and (b) the apparent viscosity versus share rate for various drilling nanofluids.

Figure $6 \mathrm{~b}$ shows that the drilling nanofluid samples have shear thinning behavior, i.e. at low shear rates the viscosity increases and decreases at high shear rates.

The effects of nanoparticles on the rheological properties (i.e., apparent viscosity, plastic viscosity, and yield point) of various drilling nanofluid samples are compared in Figure 7 . The calculated values of apparent viscosity and plastic viscosity for the base drilling fluid in the absence of nanoparticles were $22.5 \mathrm{cP}$ and $8 \mathrm{cP}$, respectively. The experimental measurements show that the apparent viscosity and plastic viscosity of the base drilling fluid increase with the addition of nanoparticles. Moreover, the viscosity values increase with increase in concentrations of nanoparticles in the drilling fluid. The increase of drilling nanofluid viscosity can be attributed to the increase in friction between fluid layers in the presence of nanoparticles [48].

The ability of a drilling fluid to carry drill cuttings out of the annulus is evaluated by the value of the yield point, which should be high enough for proper cuttings transport. However, large yield point values generate extra pump pressure that must be inhibited. The yield point is dependent on the electro-chemical charges in the drilling fluid under flowing conditions. The predominance of the attractive forces between the particles leads to a high yield point value. 


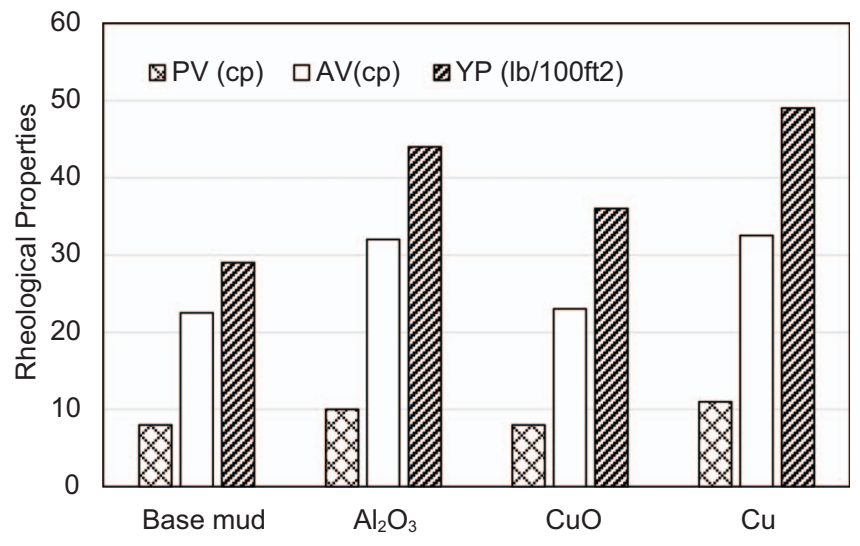

Fig. 7. Base drilling fluid and nanofluid samples rheological characteristics.

In contrast, when repulsive forces prevail, a decrease in yield point value is observed. However, the yield point value can be adjusted using various chemical additives [49].

The measured yield point value for the base drilling fluid was $29 \mathrm{lb} / 100 \mathrm{ft}^{2}$. Figure 7 shows that increase in concentration of nanoparticles in the base drilling fluid increases the yield point value. The maximum value of yield point (i.e., $49 \mathrm{lb} / 100 \mathrm{ft}^{2}$ ) was obtained by addition of copper nanoparticles to the drilling fluid. It is obvious that the drilling nanofluids prepared by addition of various nanoparticles exhibit better rheological properties than the base drilling fluid [50].

The value of gel strength of a fluid shows the minimum shear stress required to start movement in fluids and is obtained in two ways: measurement immediately after preparation of the drilling fluid (10 s GS) and measurement after a rest for $10 \mathrm{~min}$ (10 min GS) [51, 52].

The measured $10 \mathrm{~s}$ GS and $10 \mathrm{~min}$ GS of the base drilling fluid were $28\left(\mathrm{lb} / 100 \mathrm{ft}^{2}\right)$ and $31\left(\mathrm{lb} / 100 \mathrm{ft}^{2}\right)$, respectively. The gel strength values of the drilling nanofluid samples prepared with the addition of $0.9 \mathrm{wt} \%$ nanoparticles are compared in Figure 8. As shown in this figure added nanoparticles increase the gel strength of the base drilling fluid. The maximum gel strength values (i.e., $51 \mathrm{lb} / 100 \mathrm{ft}^{2}$ after $10 \mathrm{~s}$ and $69 \mathrm{lb} / 100 \mathrm{ft}^{2}$ after $10 \mathrm{~min}$ ) were obtained for copper nanoparticles.

\subsection{Filtration test}

The filtrate loss of drilling fluid samples were measured under 100 psi pressure and ambient temperature. The filter loss results for the base drilling fluid in the presence of various nanoparticles are shown in Figure 9. The filtrate loss volume for the base drilling fluid was measured $14.2 \mathrm{~mL}$. The experimental results revealed that drilling fluid samples formulated by adding nanoparticles had better filtration characteristics than the base drilling fluid and showed lower filtrate losses. The best reduction in the filtrate loss was achieved by adding copper oxide and copper nanoparticles at a concentration $0.9 \mathrm{wt} \%$ to the base drilling fluid. The mud cake thickness nearly remained unchanged within the value of $0.15 \mathrm{~cm}$ by adding

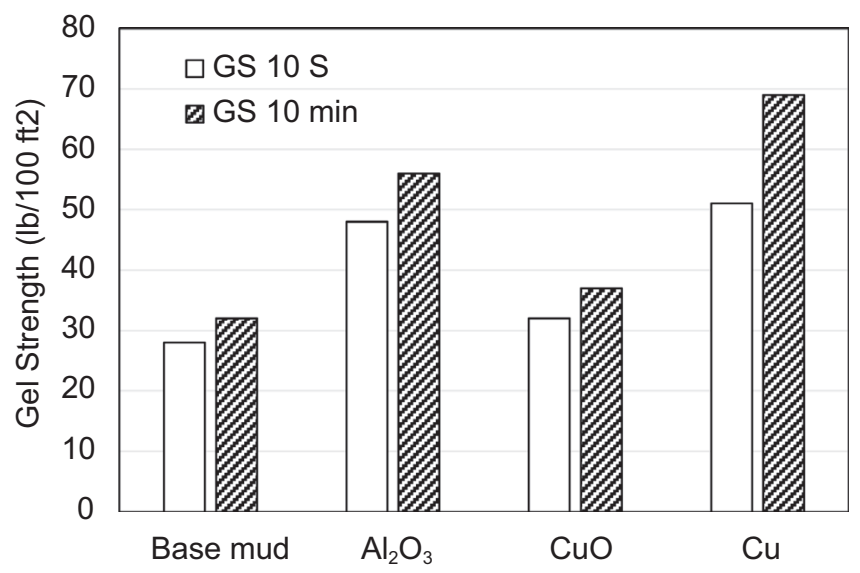

Fig. 8. Gel strength of the base drilling fluid and nanofluid samples.

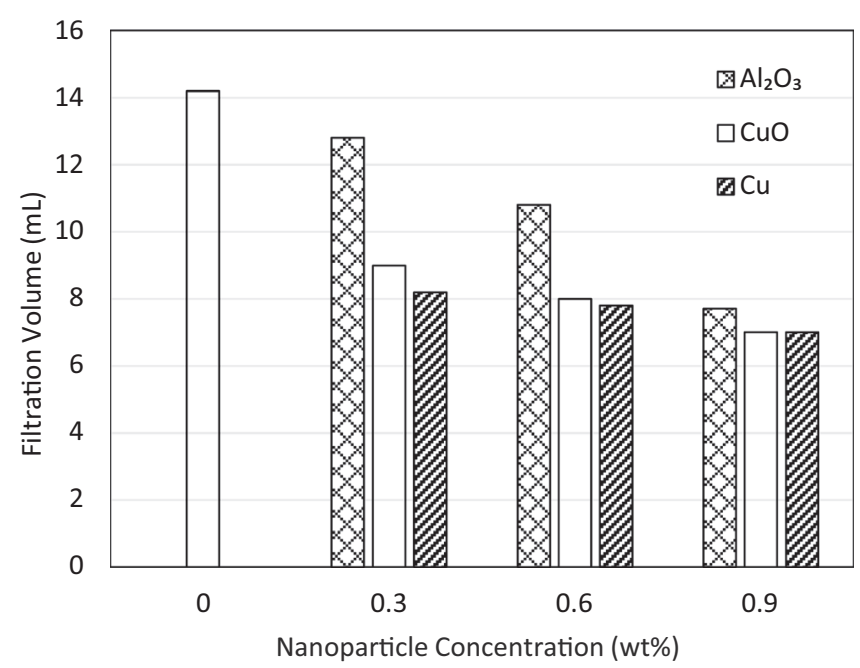

Fig. 9. Filtration volume for base drilling fluid and nanofluid samples.

nanoparticles at low concentrations (i.e., $<1 \mathrm{wt} \%$ ). It can be concluded that the presence of nanoparticles with small content did not have a significant effect on the mud cake layer thickness.

In fact, nanoparticles in the drilling fluid fill the pores and form a tight filter cake which reduces the filtrate loss. Drilling fluids should also have favorable filtration characteristics such as an acceptable fluid loss and dense filter cakes, which is preferred for decreased lost circulation, reduced formation damage, and wellbore collapse prevention [53, 54].

The filter cakes permeability can be calculated according to Darcy's law:

$$
k=\left(\frac{\mathrm{d} V_{f}}{\mathrm{~d} t}\right) \frac{\mu h_{c}}{A \Delta p},
$$

where $V_{f}, h_{c}$ and $A$ are the filtrate volume, filter cake thickness and filter cake cross sectional area, respectively. 
Table 2. Permeability of filter cakes for various drilling nanofluids.

\begin{tabular}{lcc}
\hline Drilling fluid & $\begin{array}{c}\text { Nanoparticle } \\
\text { concentration }(\mathrm{wt} \%)\end{array}$ & $\begin{array}{c}\text { Permeability } \\
(\mu \mathrm{d})\end{array}$ \\
\hline Base mud & 0 & 2.67 \\
Base mud $+\mathrm{Al}_{2} \mathrm{O}_{3}$ & 0.3 & 2.11 \\
nanoparticles & 0.6 & 1.83 \\
& 0.9 & 1.27 \\
Base mud $+\mathrm{CuO}$ & 0.3 & 1.91 \\
nanoparticles & 0.6 & 1.48 \\
& 0.9 & 0.84 \\
Base mud $+\mathrm{Cu}$ & 0.3 & 1.54 \\
nanoparticles & 0.6 & 1.28 \\
& 0.9 & 0.73 \\
\hline
\end{tabular}

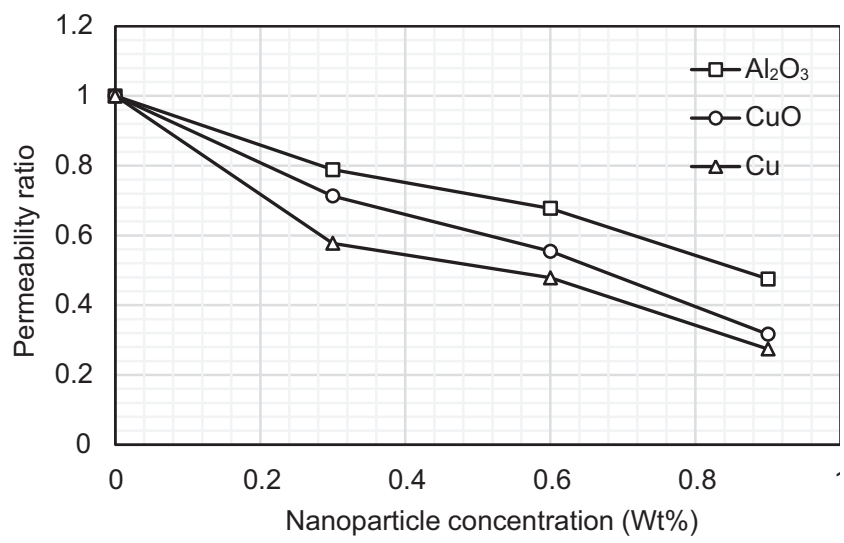

Fig. 10. Permeability of filter cakes at different concentrations of nanoparticles.

To calculate the correct value of filter cake permeability as a function of time, $\frac{\mathrm{d} V_{f}}{\mathrm{~d} t}$ should be obtained from the slope of the fluid filtration volume against the time at the corresponding time. The effects of nanoparticles concentration on the permeability of filter cakes are illustrated in Table 2. A reducing trend was observed for filter cakes permeability by increasing the nanoparticles mass fraction. The permeability reduction of filter cakes in the presence of nanoparticles resulted from more dense cake structure created by the added solid particles. This characteristic provides excellent applicability of nanofluid enhanced drilling mud: the lesser the filter cake permeability the lesser filtrate invasion into original reservoir resulting lesser formation damage providing substantially higher wellbore productivity behavior in post-drilling operations.

The ratio of the filter cakes permeability for drilling nanofluids versus the base drilling fluid at different concentrations of nanoparticles is presented in Figure 10. It is apparent that, addition of a small volume of nanoparticles can reduce the filter cake permeability and consequently the formation damage. In fact, nanoparticles with small dimensions can seal the pores in the filter cake and enhance the filtration properties of the drilling mud.

The size of dispersed nanoparticles in the base drilling fluid has a significant effect on filter cake permeability. Therefore, to diminish the formation damage, the nanoparticles size can be adjusted by changing the preparation techniques for subsurface formations with different pore diameters.

\section{Conclusion}

Considering the importance of efficient drill string and bit cooling by the drilling fluid, especially in deep drilling operations, the variations of thermal characteristics (i.e., thermal conductivity and specific heat capacity) of water-based drilling nanofluid in the presence of aluminum oxide, copper oxide and copper nanoparticles were investigated experimentally. In addition, the effect of nanoparticles on the rheology, and filtration characteristics of the drilling fluid were studied. It was concluded that nanoparticles are able to play an important role in enhancement of the thermal and rheological characteristics, decreasing fluid loss and formation damage during drilling operation.

The experimental results indicated that addition of nanoparticles to water-based drilling fluids enhances the specific heat capacity nonlinearly. A maximum value of $15.6 \%$ increase in the specific heat capacity compared to the base sample was observed with the addition of copper nanoparticles with a mass fraction of $0.9 \%$. The observed enhancements are attributed to the high specific surface area of the nanoparticles, which leads to higher specific surface energies. The increase of heat capacity for the drilling nanofluids varied with the type and concentration of nanoparticles. The experimental measurements showed that the enhancement rate of heat capacity with the addition of copper nanoparticles is faster than that with the other nanoparticles. The shear stress variation versus shear rate for all drilling nanofluid samples represented viscoplastic shear thinning behavior, and the best fitted model was found to be the Herschel-Bulkley model. The results revealed that adding nanoparticles, increases the viscosity, yield point, and gel strength of the base drilling fluid. The maximum increase in rheological properties were obtained with copper nanoparticles at a concentration of $0.9 \mathrm{wt} \%$.

On the other hand, the fluid loss of the studied samples was reduced in the presence of nanoparticles. The addition of nanoparticles in low concentration $(<1 \mathrm{wt} \%)$ reduced the fluid loss and therefore formation damage by pore plugging mechanism. The minimum filter cake permeability was calculated for copper nanofluids. Increasing the nanoparticles concentration did not affect the filter cake thickness over the studied range of concentrations.

It should be declared that simultaneous improvement of thermal conductivity and specific heat capacity is needed to enhance the heat transfer characteristics of drilling fluids, especially in deep drilling operations. This study has clearly confirmed that the presence of nanoparticles in water-based 
drilling fluids favorably changes the thermal as well as rheological and filtration characteristics of the water-base drilling fluid which should be considered for industrial applications.

\section{References}

1 Fink J. (2015) Petroleum engineer's guide to oil field chemicals and fluids, Gulf Professional Publishing, Oxford, UK.

2 Henaut I., Pasquier D., Rovinetti S., Espagne B. (2015) HPHT Drilling Mud Based on Environmently-Friendly Fluorinated Chemicals, Oil Gas Sci. Technol. - Rev. IFP Energies nouvelles 70, 917-930.

3 Bourgoyne A.T., Millheim K.K., Chenevert M.E., Young F.S. (1991) Applied drilling engineering, Society of Petroleum Engineers, Richardson.

4 Karthikeyan N.R., Philip J., Raj B. (2008) Effect of clustering on the thermal conductivity of nanofluids, $J$. Mater. Chem. Phys. 109, 50-55.

5 Michailov M.D., Milchev V.A., Yordanov V.Y., Pavlov D.K. (1990) Thermodynamics and heat transfer, Technical, Sofia.

6 Ghosn R., Mihelic F., Hochepied J.F., Dalmazzone D. (2017) Silica nanoparticles for the stabilization of $\mathrm{W} / \mathrm{O}$ emulsions at HTHP conditions for unconventional reserves drilling operations, Oil Gas Sci. Technol. - Rev. IFP Energies nouvelles 72, 21, 1-13.

7 Wang K., Jiang G., Liu F., Yang L., Nia X., Wang J. (2018) Magnesium aluminum silicate nanoparticles as a highperformance rheological modifier in water-based drilling fluids, Appl. Clay Sci. 161, 427-435.

8 Zhang H., Zhong Y., She J., Kuang J. (2019) Experimental study of nano-drilling fluid based on nano temporary plugging technology and its application mechanism in shale drilling, Appl. Nanosci. 9, 8, 1637-1648.

9 Parizad A.H., Khorram Ghahfarokhi A., Shahbazi K., Daryasafar A., Sayahi T., Kalantari Meybodi M. (2019) Experimental investigation of the effect of $\mathrm{TiO}_{2}$ nanofluid and $\mathrm{KCl}$ salt on polymeric water-based drilling fluid properties, Oil Gas Sci. Technol. - Rev. IFP Energies nouvelles 74, 9, 1-11.

10 Movahedi H., Vasheghani F.M., Jamshidi S. (2017) Application of Hydrated Basil Seeds (HBS) as the herbal fiber on hole cleaning and filtration control, J. Pet. Sci. Eng. 152, 212-228.

11 Vajjha R.S., Das D.K. (2009) Specific heat measurement of three nanofluids and development of new correlations, $J$. Heat Transf. 131, 071601.

12 Zhou S.Q., Ni R. (2008) Measurement of the specific heat capacity of water-based $\mathrm{Al}_{2} \mathrm{O}_{3}$ nanofluid, Appl. Phys. Lett. 92, 093123.

13 O'Hanley H., Buongiorno J., McKrell T., Hu L.W. (2012) Measurement and model validation of nanofluid specific heat capacity with differential scanning calorimetry, Adv. Mech. Eng. 4, 181079.

14 Sekhar Y.R., Sharma K.V. (2015) Study of viscosity and specific heat capacity characteristics of water-based $\mathrm{Al}_{2} \mathrm{O}_{3}$ nanofluids at low particle concentrations, J. Exp. Nanosci. 10, 86-102.

15 Zhou L.P., Wang B.X., Peng X.F., Du X.Z., Yang Y.P. (2009) On the specific heat capacity of $\mathrm{CuO}$ nanofluid, $A d v$. Mech. Eng. 2, 172085.
16 Shin D., Banerjee D. (2010) Enhanced specific heat of silica nanofluid, J. Heat Transf. 133, 2, 024501.

17 William J.K.M., Ponmania S., Samuel R., Nagarajan R., Sangwai J.S. (2014) Effect of $\mathrm{CuO}$ and $\mathrm{ZnO}$ nanofluids in xanthan gum on thermal, electrical and high pressure rheology of water-based drilling fluids, J. Pet. Sci. Eng. 117, 15-27.

18 Sadegh H.S., Amrollahi A., Rashidi A.M., Soleymani M., Rayatdoost S. (2016) The effect of nanoparticles on the heat transfer properties of drilling fluids, J. Pet. Sci. Eng. 146, 183-190.

19 Baghbanzadeh M., Rashidi A.M., Rashtchian D., Lotfi R., Amrollahi A. (2012) Synthesis of spherical silica/multiwall carbon nanotubes hybrid nanostructures and investigation of thermal conductivity of related nanofluids, Thermochim. Acta 549, 87-94.

20 Anwar Bég O., Sanchez Espinoza D.E., Kadir A., Shamshuddin M.D., Sohail A. (2018) Experimental study of improved rheology and lubricity of drilling fluids enhanced with nano particles, Appl. Nanosci. 8, 5, 1069-1090.

21 Dhiman P., Cheng Y., Zhang Y., Patil S. (2018) Experimental investigation of the influence of nanoparticles on water-based mud, Appl. Nanosci. 8, 3, 511-526.

22 Pakdaman E., Osfouri S., Azin R., Niknam K., Roohi A. (2019) Improving the rheology, lubricity, and differential sticking properties of water-based drilling muds at high temperatures using hydrophilic Gilsonite nanoparticles, Colloids Surf. A 582, 123930.

23 Zhuang G., Zhang Z., Jaber M. (2019) Organoclays used as colloidal and rheological additives in oil-based drilling fluids: An overview, Appl. Clay Sci. 177, 1, 63-81.

24 Afolabi R.O., Orodu O.D., Seteyeobot I. (2018) Predictive modelling of the impact of silica nanoparticles on fluid loss of water based drilling mud, Appl. Clay Sci. 151, 37-45.

25 Zhu H.T., Zhang C.Y., Yin Y.S. (2004) Rapid synthesis of copper nanoparticles by sodium hypophosphite reduction in ethylene glycol under microwave irradiation, J. Cryst. Growth 270, 722-728.

26 Paul G., Philip J., Raj B., Das P.K., Manna I. (2011) Synthesis, characterization, and thermal property measurement of nano- $\mathrm{Al}_{95} \mathrm{Zn}_{05}$ dispersed nanofluid prepared by a two-step process, Int. J. Heat Mass Transf. 54, 3783-3788.

27 Hajipour M., Molaei D.A. (2014) Mixed-convection flow of $\mathrm{Al}_{2} \mathrm{O}_{3}-\mathrm{H}_{2} \mathrm{O}$ nanofluid in a channel partially filled with porous metal foam: Experimental and numerical study, Exp. Therm. Fluid Sci. 53, 49-56.

28 Hohne G. (2003) Differential scanning calorimetry, Springer, New York, NY, pp. 148-160.

29 Green D.W., Perry R.H. (2007) Perry's chemical engineers' handbook, McGraw-Hill, New York, USA.

30 Kleinstreuer C., Feng Y. (2011) Experimental and theoretical studies of nanofluid thermal conductivity enhancement: A review, Nanoscale Res. Lett. 6, 229-242.

31 API (American Petroleum Institute). (2003) Recommended practice for field testing water-based drilling fluids, 3rd ed., API 13B-1.

32 Sekhar Y.R., Sharma K.V. (2015) Study of viscosity and specific heat capacity characteristics of water-based $\mathrm{Al}_{2} \mathrm{O}_{3}$ nanofluids at low particle concentrations, J. Exp. Nanosci. 10, 86-102.

33 Zhou S.Q., Ni R. (2008) Measurement of the specific heat capacity of water-based $\mathrm{Al}_{2} \mathrm{O}_{3}$ nanofluid, Appl. Phys. Lett. 92, 093123. 
34 Chieruzzi M., Cerritelli G.F., Miliozzi A., Kenny J.M. (2013) Effect of nanoparticles on heat capacity of nanofluids based on molten salts as PCM for thermal energy storage, Nanoscale Res. Lett. 8, 448-457.

35 Heilmann P. (2013) Evaluation, neuentwicklung und optimierung des eigenschaftsprofils von salzschmelzen für die verwendung als wärmeträgerfluide, $P h D$ Thesis, Bergische Universität, Wuppertal.

36 Lasfargues M., Geng Q., Cao H., Ding Y. (2015) Mechanical dispersion of nanoparticles and its effect on the specific heat capacity of impure binary nitrate salt mixtures, Nanomaterials 5, 1136-1146.

37 Angayarkanni S.A., Sunny V., Philip J. (2015) Effect of nanoparticle size, morphology and concentration on specific heat capacity and thermal conductivity of nanofluids, $J$. Nanofluids 4, 302-309.

38 Shin D., Banerjee D. (2011) Enhancement of specific heat capacity of high-temperature silica-nanofluids synthesized in alkali chloride salt eutectics for solar thermal-energy storage applications, Int. J. Heat Mass Transf. 54, 1064-1070.

39 Evans W., Fish J., Keblinski P. (2006) Role of Brownian motion hydrodynamics on nanofluid thermal conductivity, Appl. Phys. Lett. 88, 9, 093116.

40 Evans W., Prasher R., Fish J., Meakin P., Phelan P., Keblinski P. (2008) Effect of aggregation and interfacial thermal resistance on thermal conductivity of nanocomposites and colloidal nanofluids, Int. J. Heat Mass Transf. 51, 5, 1431-1438.

41 Li L., Zhang Y., Ma H., Yang M. (2010) Molecular dynamics simulation of effect of liquid layering around the nanoparticle on the enhanced thermal conductivity of nanofluids, $J$. Nanopart. Res. 12, 811-821.

42 Lu M.C., Huang C.H. (2013) Specific heat capacity of molten salt-based alumina nanofluid, Nanoscale Res. Lett. 8, 1, 292299.

43 Zhou S.Q., Ni R. (2008) Measurement of the specific heat capacity of water-based $\mathrm{Al}_{2} \mathrm{O}_{3}$ nanofluid, Appl. Phys. Lett. $\mathbf{9 2 ,} 093123$.
44 Zhou L.P., Wang B.X., Peng X.F., Du X.Z., Yang Y.P. (2010) On the specific heat capacity of $\mathrm{CuO}$ nanofluid, $A d v$. Mech. Eng. 2, 1-4.

45 Farbod M., Kouhpeymani R., Noghreh Abadi A.R. (2015) Morphology dependence of thermal and rheological properties of oil-based nanofluids of $\mathrm{CuO}$ nanostructures, Colloids Surf. A 474, 71-75.

46 Wang B., Wang X., Lou W., Hao J. (2012) Thermal conductivity and rheological properties of graphite/oil nanofluids, Colloids Surf. A 414, 125-131.

47 Yh C., Yusup S., Chok V.S. (2014) Study on the effect of nanoparticle loadings in base fluids for improvement of drilling fluid properties, J. Adv. Chem. Eng. 4, 3, 1-5.

48 Kumar Sharma A., Kumar Tiwari A., Rai Dixit A. (2016) Rheological behaviour of nanofluids: A review, Renew. Sust. Energy Rev. 53, 779-791.

49 El-Sukkary M.M.A., Ghuiba F.M., Sayed G.H., Abdou M.I., Badr E.A., Tawfik S.M., Negm N.A. (2014) Evaluation of some vanillin-modified polyoxyethylene surfactants as additives for water based mud, Egypt J. Petrol. 23, 7-14.

50 Dahlem A. (2013) Automatic adjustment of drilling fluid properties, Master's Thesis, University of Stavanger, Norway.

51 Dardir M.M., Ibrahime S., Soliman M., Desouky S.D., Hafiz A.A. (2014) Preparation and evaluation of some esteramides as synthetic based drilling fluids, Egypt J. Petrol. 23, 35-43.

52 Hafiz A.A., Abdou M.I. (2003) Synthesis and evaluation of polytriethanolamine monooleates for oil-based muds, $J$. Surfactants Deterg. 6, 3, 243-251.

53 Durand C., Lecourtier J., Rosenberg E., Loeber L. (1996) Relationship between composition, structure and permeability of drilling filter cakes, Oil Gas Sci. Technol. - Rev. IFP Energies nouvelles 51, 777-788.

54 Vasheghani F.M., Soleimani R., Jamshidi S., Salehi S. (2014) Development of a dynamic model for drilling fluid's filtration: Implications to prevent formation damage, in: SPE International Symposium and Exhibition on formation Damage, Lafayette. 